\section{Mitgliederversammlung bestimmt neuen Vorstand}

\author{
Eingebettet in das Programm des 29. ÄDA-Kongresses in Wiesbaden \\ fand am Samstag, dem 16. September 2006, auch die diesjährige \\ Mitgliederversammlung des ÄDA statt. Wichtigster Tagesordnungs- \\ punkt war die Wahl des neuen Vorstandes.
}

Z u Anfang der Mitgliederversammlung standen die Preisverleihungen auf dem Programm. Priv.-Doz. Dr. Dieter Stiller, Fürstenwalde, erhielt die Goldene Ehrennadel des Ärzteverbandes Deutscher Allergologen. Die Laudatio hielt Dr. Uta Rabe. Prof. Dr. Wolfgang Leupold, Dresden, wurde mit der Viktor-Ruppert-Medaille des Ärzteverbandes Deutscher Allergologen ausgezeichnet, Laudator war Dr. Wolfgang Rebien. Der Klaus-Kalveram-Preis 2006 schließlich ging an Dr. Eike Hollenbach, Leipzig. Prof. Dr. Günther Forck überreichte die Urkunde im Namen der Klaus-Kalveram-Stiftung.

Als wichtigster Tagesordnungspunkt folgte dann die Wahl des neuen Vorstandes. Prof. Dr. Dr. Johannes Ring stellte zunächst den Antrag auf Entlastung des alten Vorstandes. Der Antrag wurde einstimmig - bei Enthaltung der Vorstandsmitglieder - angenommen. Danach trat der Vorstand in seiner alten Zusammensetzung zurück, Prof. Ring übernahm als Wahlleiter kommissarisch

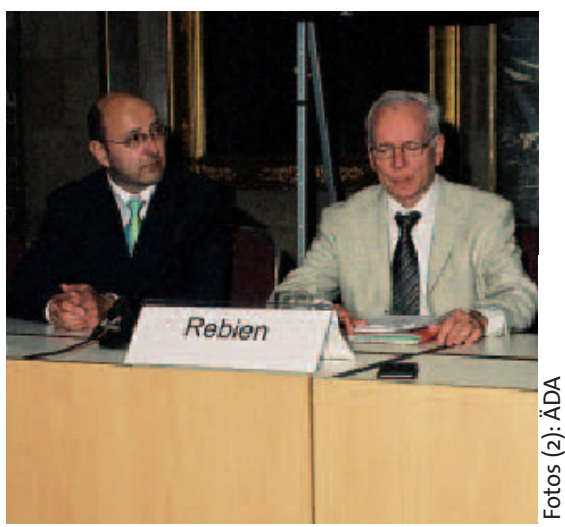

Der Vorname bleibt: der neue ÄDAPräsident Prof. Dr. Wolfgang Czech (links) und der scheidende ÄDAPräsident Dr. Wolfgang Rebien (rechts). den Vorsitz der Mitgliederversammlung. Dr. Rebien als scheidender Präsident stellte die Vorschläge für den Vorstand in der neuen Legislaturperiode vor: Es standen zur Wahl der bisherige Vizepräsident Prof. Dr. Wolfgang Czech als neuer Präsident, Prof. Dr. Hans F. Merk als neuer Vizepräsident sowie Prof. Dr. Wolfgang W. Schlenter wie bisher auch als Schatzmeister. Das Plenum stimmte offen über den Wahlvorschlag ab, der ohne Gegenstimmen mit drei Enthaltungen angenommen wurde.

Prof. Czech übernahm im Anschluss als neuer Präsident die Leitung der Mitgliederversammlung. Sein Vorschlag für die Beisitzer des erweiterten Vorstandes wurde ohne Gegenstimmen bei acht Enthaltungen angenommen. Die $\mathrm{Zu}$ sammensetzung des erweiterten Vorstandes hat sich geändert: Dr. Josef Wenning scheidet aus dem erweiterten Vorstand aus und geht in den Beirat. Und eine Änderung findet im Beirat statt: Prof. Jochen Sennekamp scheidet aus dem Beirat aus.

sersys

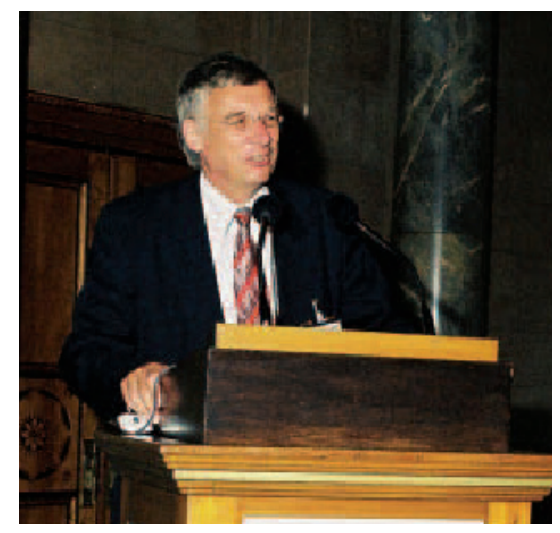

Dr. Josef Wenning schied als Beisitzer aus dem erweiterten Vorstand aus und berichtete über seine langjährige Tätigkeit im Vorstand des ÄDA.

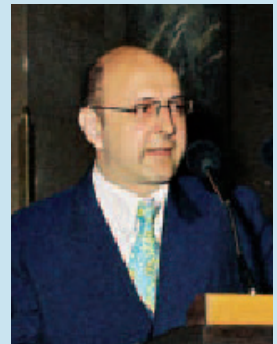

Pråsident

Prof. Dr. Wolfgang Czech

Venerologie - Allergologie

Benediktinerring 10,78050 VS-Villingen

Tel.: (o 77 21) 55411

Fax: (0 77 21) 57504

E-Mail: prof.czech@t-online.de

\section{Vizepräsident}

Prof. Dr. Hans F. Merk

Klinik für Dermatologie und Allergologie, Universitätsklinikum der RWTH, Pauwelsstraße 30, 52074 Aachen

Tel.: (02 41) 80 88-3 30

Fax: (02 41) 8082413

E-Mail:hans.merk@post.rwth-aachen.de

\section{Schatzmeister}

Prof. Dr. Wolfgang W. Schlenter HNO-Abteilung, Katharina-KasperKlinikum, Sankt-Marien-Krankenhaus, Richard-Wagner-Straße 14,

60318 Frankfurt/M.

Tel.: (o 69) 15631266

Fax: (o 69) 15631140

E-Mail:schlenter@em.uni-frankfurt.de

\section{Beisitzer}

_ Prof. Dr. Thomas Fuchs, Göttingen

— Priv.-Doz. Dr. Kirsten Jung, Erfurt

_ Dr. Werner Kersten, Moers

— Prof. Dr. Ludger Klimek, Wiesbaden

_ Prof. Dr. Wolfgang Leupold, Pirna

- Dr. Uta Rabe, Treuenbrietzen

_Dr. Wolfgang Rebien, Hamburg

— Prof. Dr. Wolfgang Wehrmann, Münster

\section{Beirat}

-Priv.-Doz. Dr. Claus-E. Lange, Bonn _Dr. Josef Wenning, VS-Villingen

\section{Geschäftsstelle}

Service Systems

Carin Fresle und Ursula Raab Blumenstraße 14, 63303 Dreieich

Tel.: (о 61 03) 62273

Fax: (0 61 03) 697019

E-Mail:aeda@sersys.de 